\title{
O Uso de Mapas Conceituais no Ensino da Disciplina de Geofísica do Petróleo no Curso de Engenharia de Petróleo e Gás da Universidade Federal do Amazonas - UFAM
}

Simas, J. de L., UFAM; Basilici,G., UNICAMP

Copyright 2018, SBGf - Sociedade Brasileira de Geofísica

Este texto foi preparado para a apresentação no VIII Simpósio Brasileiro de Geofísica, Salinópolis, 18 a 20 de setembro de 2018. Seu conteúdo foi revisado pelo Comitế Técnico do VIII SimBGf, mas não necessariamente representa a opinião da SBGf ou de seus associados. É proibida a reprodução total ou parcial deste material para propósitos comerciais sem prévia autorização da SBG.

\section{Resumo}

No geral os cursos em Engenharia de Petróleo preparam profissionais para atuar nos processos de implantação e operacionalização nas unidades da indústria de petróleo e gás. Com isso, para um melhor desempenho dos discentes no curso é necessário o uso de metodologias de ensino que possibilitem o processo de ensinoaprendizagem. Por exemplo, o uso de mapas conceituais, proporcionando assim um envolvimento mais efetivo na formação desses alunos. Para a elaboração e desenvolvimento dessa proposta didática seguiram-se as seguintes etapas: (1) Pesquisa pormenorizada acerca de usos de recursos didáticos na graduação para o ensino de Geociências; (2) Estudo sobre técnicas e recursos de ensino-aprendizagem e possíveis papéis didáticos; (3) As bases para o desenvolvimento da aplicação das propostas didáticas.

\section{Introdução}

O curso de Engenharia de Petróleo e Gás da Universidade Federal do Amazonas (UFAM) iniciou suas atividades em 2010, com sua primeira turma de formandos em 2015. A disciplina de Geofísica do Petróleo (FTP002) faz parte do eixo estruturante em Geologia e possui como pré-requisito a disciplina de Geologia Geral (IEG053).

Atualmente a disciplina de Geofísica do Petróleo vem sendo ofertada no quinto semestre do Curso de Engenharia de Petróleo e Gás. Em sua ementa a disciplina FTP002 contempla uma vasta gama de conteúdo voltado para o uso dos métodos geofísicos especificamente na exploração de hidrocarbonetos.

A dificuldade no entendimento desta disciplina observouse desde a primeira turma, ao qual para que houvesse um maior envolvimento dos discentes junto ao eixo estruturante da Geologia, ofertou-se atividades extra curriculares, como projetos de extensão, incluindo a divulgação do Curso de Engenharia de Petróleo nas escolas de ensino médio no município de Manaus/AM. Nos últimos anos observa-se uma grande retenção de alunos na disciplina de Geofísica do Petróleo por conta talvez da quantidade de assunto abrangido em sua ementa atual. Sendo que a falta de laboratório específico, também é um agravante para que haja um bom entendimento dos conteúdos abrangidos na disciplina.

De um modo geral, no ensino das Geociências, a utilização de recursos visuais amplia as possibilidades de se trabalhar com a dimensão do espaço e tempo, mas também temos o problema que as Geociências compartilha com as outras ciências que é o da representação das explicações, que normalmente é apresentada em duas dimensões (o papel) (COMPIANI,2006).

No ensino superior é importante a elaboração de práticas para o desenvolvimento do processo ensinoaprendizagem, principalmente nas Engenharias, onde essas práticas devem envolver: a motivação, a curiosidade e a participação para assim construir o conhecimento. Tyler (1949) dizia que a aprendizagem ocorre através do comportamento ativo do aluno: o que ele faz, ele aprende. E não o que o professor faz. Se os alunos devem aprender os resultados desejados de forma razoavelmente eficaz, então a tarefa fundamental do professor é fazer com que os alunos se envolvam em atividades que resultarão na obtenção desses resultados (Biggs, 2003).

O uso dos Mapas Conceituais em Geofísica do Petróleo, é uma ferramenta metodológica utilizada como estratégia de ensino e estudo facilitando assim o processo de ensino-aprendizagem na graduação, especificamente nas Engenharias.

\section{Metodologia/ Problema Investigado}

Os Mapas Conceituais são estruturas esquemáticas que representam conjuntos de ideias e conceitos dispostos em uma espécie de rede de proposições, de modo a apresentar mais claramente a exposição do conhecimento e organizá-lo segundo a compreensão cognitiva do seu idealizador.

Portanto, são representações gráficas, que indicam relações entre palavras e conceitos, desde aqueles mais abrangentes até os menos inclusivos. São utilizados para a facilitação, a ordenação e a sequenciação hierarquizada dos conteúdos a serem abordados, de modo a oferecer estímulos adequados à aprendizagem (AUSUBEL,2003).

Baseando-se na Teoria da Aprendizagem Significativa (AS) de David Ausubel, Novak definiu Mapa Conceitual como uma representação gráfica, em duas dimensões, de determinado conjunto de conceitos, sendo construído de tal forma que as relações entre eles sejam evidentes. 


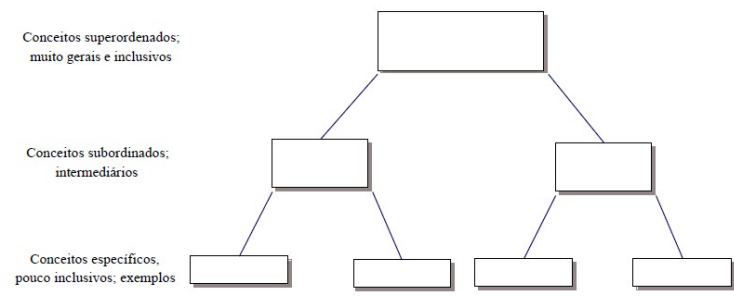

Figura 1 - Modelo de Mapa Conceitual, segundo a teoria de Ausubel.

Os Mapas Conceituais forma utilizados principalmente em dois tópicos da disciplina de Geofísica do Petróleo: Definição de Geofísica (conceitos e aplicações) e Método Gravimétrico (conceitos, fundamentação teórica, equipamentos e aplicações).

As práticas com os mapas conceituais seguiram os seguintes passos:

1 - Anotar os principais termos ou conceitos acerca do tópico;

2 - Identificar os conceitos mais gerais, os intermédios e os específicos;

3 - Começar a construir o mapa de conceitos: os conceitos são contornados com um círculo (oval ou outra forma); o conceito mais geral é localizado no topo; os conceitos intermediários são colocados abaixo do geral e os específicos abaixo do intermediário;

4 - Traçar a linha de ligação entre os conceitos;

5 - As linhas de ligação dos círculos são "etiquetadas" com as palavras de ligação indicando como os conceitos estão relacionados - proposições;

6 - Com o mapa pronto é feita a revisão do mapa conceitual.

\section{Resultados}

No geral os mapas conceituais podem ser utilizados como instrumentos de ensino ou aprendizagem. Como instrumentos didáticos, os mapas conceituais podem ser usados para mostrar as relações hierárquicas entre os conceitos que estão sendo ensinados em uma aula, em uma unidade de estudo ou em um curso inteiro. Contudo os mapas conceituais não dispensam a explicação do professor.

O tópico de introdução a geofísica é apresentado definindo a geofísica e suas subdivisões. Nesta etapa, após prévia apresentação do professor, os alunos foram convidados a apresentar um mapa conceitual sobre o tema abordado. Abaixo, Figura 2, temos um modelo de mapa elaborado por um dos discentes participantes da turma:

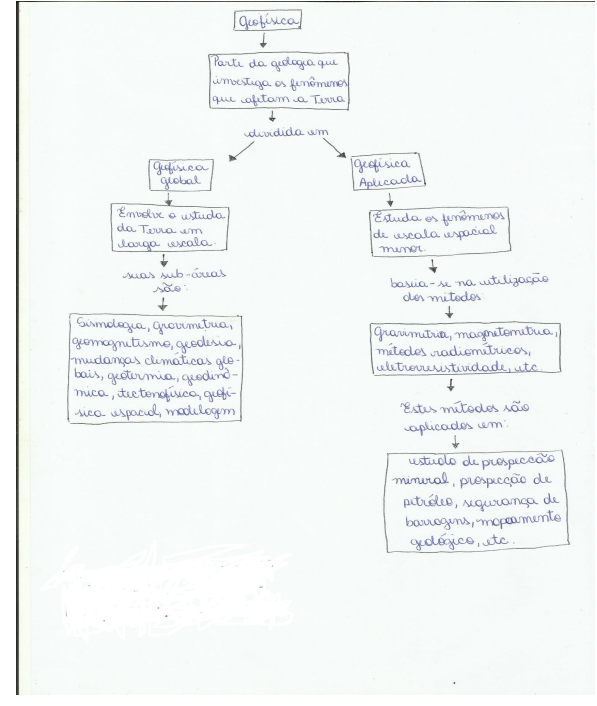

Figura 2 - Mapa Conceitual sobre as definições de Geofísica, elaborado por um dos discentes da turma.

O segundo tópico onde utilizou-se a aplicação dos mapas conceituais foi no Método Gravimétrico. Nesta etapa, após prévia apresentação do professor, onde foram vistos a fundamentação do método, os instrumentos utilizados e sua aplicação para a indústria do petróleo, os alunos foram convidados a apresentar um mapa conceitual sobre o tema abordado. Abaixo, Figura 3, temos um modelo de mapa elaborado por um dos discentes participantes da turma:

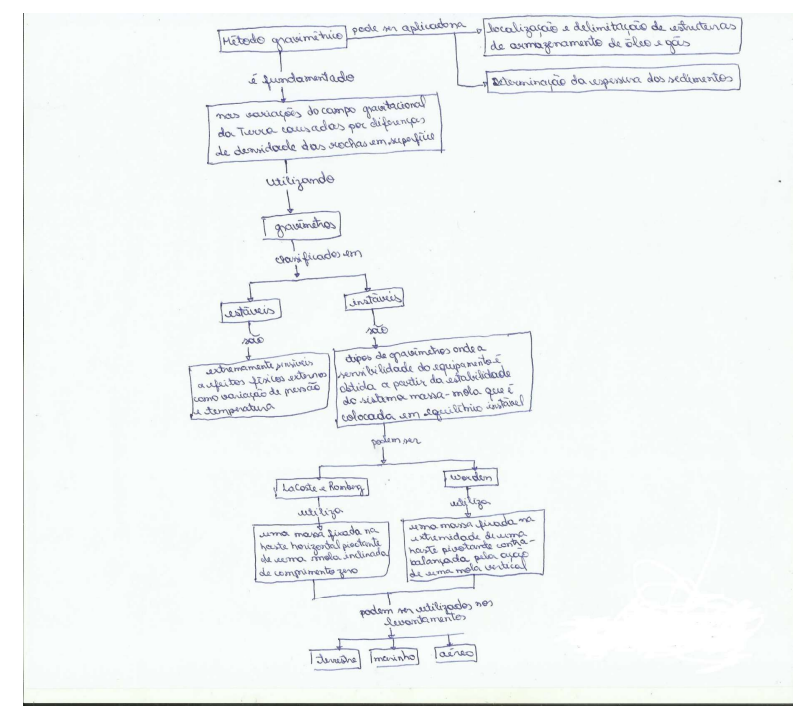

Figura 3 - Mapa Conceitual sobre o Método Gravimétrico, elaborado por um dos discentes da turma. 
Os autores esperavam obter uma avaliação da aplicação da proposta didática como contribuição para o processo de ensino-aprendizagem no curso de Engenharia de Petróleo e Gás da UFAM na disciplina de Geofísica do Petróleo.

A partir do desenvolvimento da aplicação dos mapas conceituais, pretende-se, como resultado, ter uma maior integração dos alunos com o professor da disciplina, a fim de permitir uma melhor aprendizagem não só na sala de aula, verificando assim a aplicabilidade na absorção de adquirir conhecimento nesta disciplina.

A estratégia de produção e apresentação dos mapas conceituais possibilitou uma dinâmica de classe que, em geral, apresentaria um corpo teórico, que às vezes é bastante complexo. A proposta de tal estratégia visava fixar o entendimento sobre os métodos utilizados em geofísica do petróleo para a exploração dos hidrocarbonetos.

Os mapas conceituais construídos pelos alunos foram analisados quantitativamente e, como propósito adicional, buscamos avaliar a opinião dos alunos sobre o potencial deste instrumento para facilitar a aprendizagem. Outro aspecto particular avaliado foi a contribuição para a expressão escrita, as dificuldades percebidas na construção dos diagramas, e suas vantagens e desvantagens do uso.

\section{Discussão e Conclusões}

Com a utilização da proposta didática apresentada na disciplina de Geofísica do Petróleo, os estudantes concordaram que o uso de mapas conceituais foi de extrema importância para o aprendizado dos conceitos voltados para os dois principais tópicos abordados nesta disciplina

De acordo com o resultado da análise qualitativa (onde foi levado em consideração principalmente a clareza na exposição do mapa), a produção dos mapas conceituais pelos alunos facilitou $o$ entendimento dos conceitos aplicados nos tópicos de Introdução a Geofísica e Método Gravimétrico da disciplina de Geofísica do Petróleo.

A estratégia da produção e apresentação desta proposta didática possibilitou a dinamização das aulas que, de forma geral, apresentam um corpo teórico às vezes bastante complexo. Ao propor tal estratégia objetivava-se que os discentes tivessem um melhor entendimento dos conceitos abordados nos tópicos, facilitando assim seu aprendizado.

No geral houve uma avaliação positiva da aplicação dos Mapas Conceituais pelos estudantes fomentando às correlações com outros assuntos abordados ao longo da ministração das aulas, engajamento do estudante na disciplina e fortalecimento da relação professor-aluno. 0 aluno se sentiu inserido na disciplina com o papel de "construtor" da mesma havendo uma maior participação nas atividades propostas.

\section{Agradecimentos}

A Universidade Federal do Amazonas (UFAM) pelo apoio no desenvolvimento da prática em sala de aula.

\section{Referências}

AMARAL, I. A. do; MACEDO, A. B.; CARNEIRO, C. D. R. 1976. Uma Busca de Renovação no Ensino de Geociências (A Searching For Renovation in the Geosciences Teaching). Separata do boletim Paulista de Geografia. São Paulo. 52:55-67.

AUSUBEL, D.P. Aquisição e Retenção de Conhecimentos: uma perspectiva cognitiva. Lisboa: Plátano Edições Técnicas, 2003.

AUSUBEL, D.P., NOVAK, J.D. and HANESIAN, H. Educational Psychology. New York: Holt, Rinehart and Winston, 1986.

AUSUBEL, D.P., Novak, J.D. and Hanesian, H. (1978). Educational psychology. New York: Holt, Rinehart and Winston. Publicado em português pela Editora Interamericana, Rio de Janeiro, 1980. Em espanhol por Editorial Trillas, México, 1981. Reimpresso em inglês por Werbel \& Peck, New York, 1986.

BABCOCK, E. A. 1994. Geoscience in a changing society. Episodes, 17(4):101-105.

BARBOSA R. 2003. Projeto Geo-Escola: recursos computacionais de apoio ao ensino de geociências nos níveis fundamental e médio. Campinas: Inst. Geoc., University of Campinas. 105p. (Masters degree dissert. Geosciences)

BARBOSA R. 2013. Projeto Geo-Escola: Geociências para uma escola inovadora. Campinas: Campinas: Inst. Geoc., University of Campinas. 202p. (Doctor degree. URL: $\quad$ http://www.bibliotecadigital.unicamp .br/document/?code $=000920387$.

BIGGS,J. And TANG,C.1999. Teaching for Quality Learning at University. The Society for Research into Higher Education. Third Edition.

BIGGS,J.2006. Calidad del aprendizaje Universitario. Narcea,S.A. DE EDICIONES. 2a. Edicion. Traduccion: Pablo Manzano

CARNEIRO, C.D.R; LOPES,O.R. Jogos como Instrumentos facilitadores do ensino de geociências: o Jogo sobre "O Ciclo das Rochas". Em I SIMPÓSIO DE PESQUISA EM ENSINO E HISTÓRIA DE CIÊNCIAS DA TERRA III SIMPÓSIO NACIONAL SOBRE ENSINO DE GEOLOGIA NO BRASIL. 
O Uso de Mapas Conceituais no Ensino da Disciplina de Geofísica do Petróleo no Curso de Engenharia de Petróleo e Gás 4 da Universidade Federal do Amazonas - UFAM

COMPIANI, M. Linguagem e percepção visual no ensino de Geociências. Pro-Posições. V.17 n I (49) Jan-Abr 2006.

FRODEMAN, R. L. ed. 2000. Earth matters: the Earth Sciences, phylosophy and the claims of community. Upper Saddle River: Prentice Hall. 209p.

FARIA, de Wilson. Mapas Conceituais: aplicações ao ensino, currículo e avaliação. São Paulo: EPU - Temas Básicos de Educação e Ensino, 1985.

NOVAK, J.D. \& GOWIN, D.B. (1996). Aprender a Aprender. Lisboa: Plátano Edições Técnicas, 1986. 